\title{
Egg Binding in a Female Pigeon - A Case Report
}

\author{
Lucia BEL*, Razvan CODEA, Cosmin PEŞTEAN, Ciprian OBER, Liviu OANA \\ Faculty of Veterinary Medicine, University of Agricultural Sciences and Veterinary Medicine Cluj- \\ Napoca, Calea Manastur nr. 3-5, 400035 Cluj Napoca, Romania. \\ Corresponding author: lucia.g.bel@gmail.com
}

Bulletin UASVM Veterinary Medicine 72(1) / 2015,

Print ISSN 1843-5270; Electronic ISSN 1843-5378

DOI:10.15835/buasvmcn-vm: 11105

\begin{abstract}
Egg binding is a common reproductive disorder in pet birds of all age and species. In some cases there is no evident clinical sign present, mostly due to the cause of the disorder, but also the species. In other cases, like cockatiels, finches, lovebirds or canaries, signs are more evident

A female pigeon was presented to our clinic with a history of egg laying problem. Based on history, palpation and X-Ray findings the diagnosis was that of egg binding. Due to the fact that the egg was too large to be laid, surgery was the treatment of choice.

Under general anesthesia with Butorphanol and Isoflurane, the pigeon was placed in dorsal recumbency, the surgical field was prepped and a midline coeliotomy was performed. Removal of the necrotic egg was achieved by salpingotomy and a Cushing suture (monofilament absorbable 6.0) was used for the lumen closure. The coelom was then closed using a continous pattern (poliglicolic acid 4.0) for the abdominal muscles and a single layer everted pattern for skin (silk 3.0), the last being removed 7 days after the surgical procedure.

The bird recovered well after surgery. The postoperative treatment consisted of the administration of analgesics (Meloxicam, $0.2 \mathrm{mg} / \mathrm{kg}$ ) and 10 days of antibiotics PO (Enrofloxacine $10 \mathrm{mg} / \mathrm{kg}$ ).
\end{abstract}

Keywords: dystocia, egg binding, pigeon.

\section{INTRODUCTION}

Egg binding, the impossibility of an egg to pass through the oviduct has many different causes, such as calcium metabolic disease, vitamin deficiencies, obesity, malnutrition, malformed eggs or mechanical damage to the reproductive tract (Romagnano, 1996). Although cockatiels, finches, lovebirds or canaries present more evident clinical signs (Harrison and Lightfoot, 2005) of dystocias, this reproductive disorder can be diagnosed in pigeons as well, even without the common signs, that include dyspneea, acute depression, persistent tail wagging (Speer, 1997).

\section{AIMS AND OBJECTIVES}

The objective of this short communication was to describe a case report of a female pigeon diagnosed with egg binding.

\section{MATERIALS AND METHODS}

A reproduction female pigeon was presented for consult to our clinic with the history of egg dystocia for more than 6 months, but with no life threatening clinical signs. The egg binding was confirm via X-Ray and also transcloacal palpation.

After premedication with Butorphanol (0.4 $\mathrm{mg} / \mathrm{kg}$ ), administered IM in the pectoral muscles, induction of anesthesia was achieved using Isoflurane administered on a mask. The patient was then intubated, an IV catheter was placed on the left metatarsal vein and the abdominal area was prepped for surgery.

The surgical procedure consisted of incising the skin, the abdominal muscles and after accessing the abdominal cavity and exploring the internal organs, elevation of the oviduct and extraction of the dystocic egg. The oviduct and abdominal muscles were then sutured with 

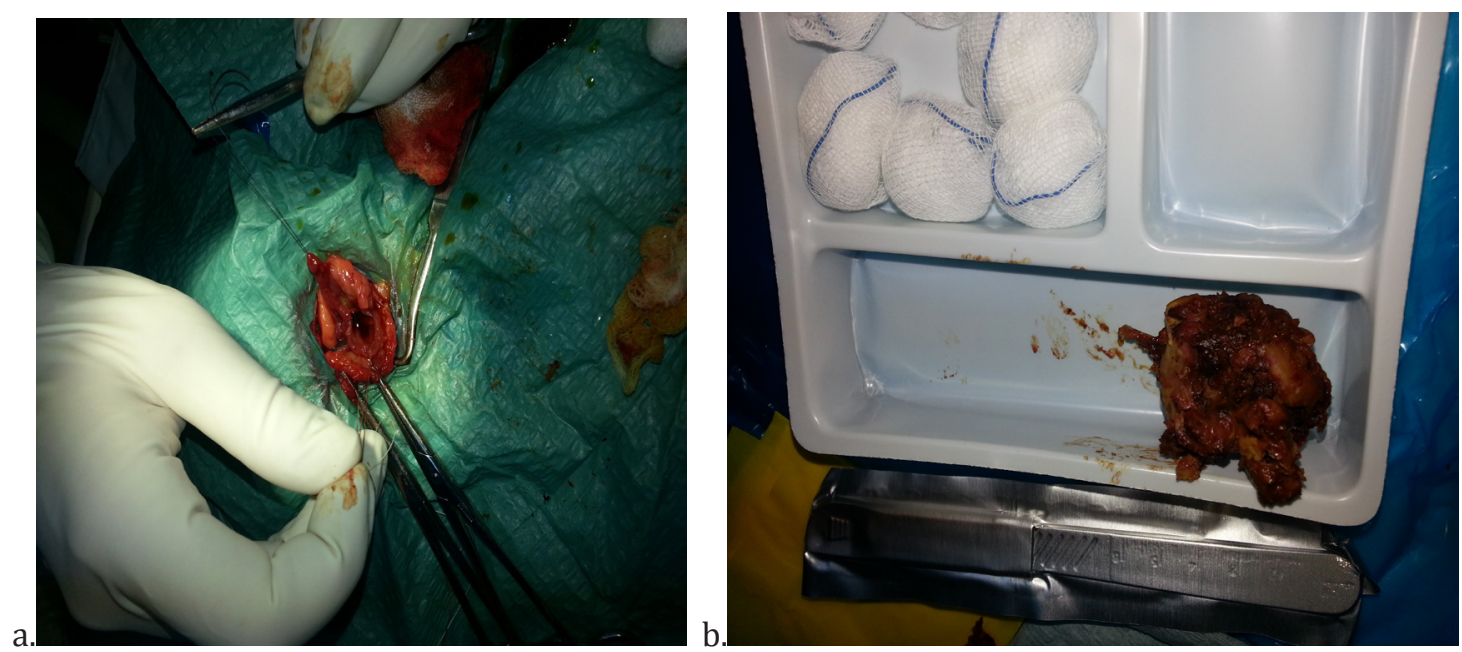

Fig. 1. (a) Isolation of the salpinx and salpingotomy; (b) Macroscopic aspect of the egg removed

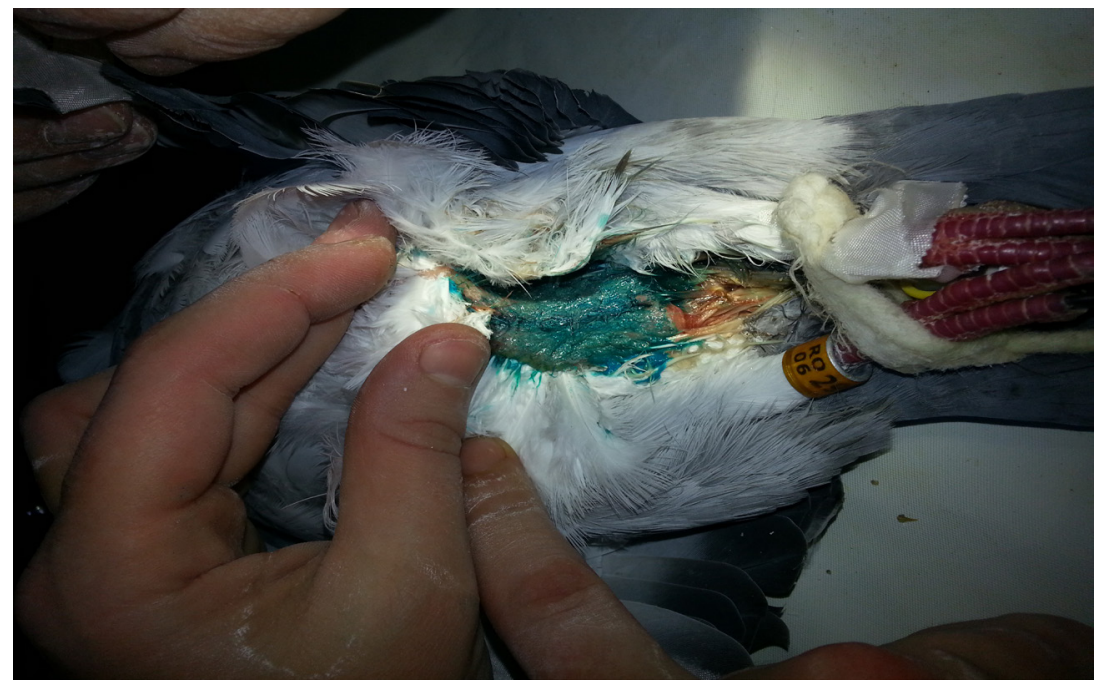

Fig. 2. Skin suture at the end of surgery

absorbable material (PGA 4.0) in a continuous pattern and the skin with silk (3.0) in a single layer everted pattern.

\section{RESULTS}

The position of the binded egg was identified by palpation. After elevating the oviduct signs of adherences were observed and after the incision of the oviductal layers, the necrotic process of the egg was confirmed. Moderate friability of the oviduct was present, but the Cushing suture (monofilament absorbable 6.0) permitted a reliable closure of the lumen. Postoperative, the pigeon received antibiotic therapy (Enrofloxacine $10 \mathrm{mg} / \mathrm{kg} \mathrm{IM}$ ) for ten days and analgesics (Meloxicam $0.2 \mathrm{mg} / \mathrm{kg}$ ) for 5 days and recovered well after surgery.

\section{CONCLUSION}

Surgical management of egg binding in this case report of a female pigeon was successful. The fact that there were no other concurrent diseases and that the egg itself was not compressing the internal organs shortened the recovery time to a minimum.

\section{REFERENCES}

1. Harrison GR, Lightfoot TL (2005). Clinical avian medicine. Vol II (18):520-539, Spix Publishing Inc., Florida.

2. Romagano A (1996). Avian obstetrics. Sem Avian Exot Pet Med 5:180-188.

3. Speer B (1997). Diseases of the urogenital system. Avian Medicine and Surgery, 633-644, WB Saunders, Philadelphia. 